\title{
Antifertility effects of porcine zona pellucida-3 immunization using permissible adjuvants in female bonnet monkeys (Macaca radiata): reversibility, effect on follicular development and hormonal profiles
}

\author{
H. Bagavant ${ }^{1}$, P. Thillai-Koothan ${ }^{2}$, M. G. Sharma ${ }^{1}$, G. P. Talwar $^{1}$ and \\ S. K. Gupta ${ }^{1}$ \\ ${ }^{1}$ Gamete Antigen Laboratory, National Institute of Immunology, New Delhi 110 067, India and \\ ${ }^{2} \mathrm{MRC}$ Reproductive Biology Unit, Centre for Reproductive Biology, Edinburgh EH3 9EW, UK
}

\begin{abstract}
Female bonnet monkeys Macaca radiata ( $n=8$, four per group) were immunized with purified $55 \mathrm{kDa}$ glycoprotein from porcine zona pellucida (ZP 3 ) and ZP3 conjugated to the $\beta$ subunit of human chorionic gonadotrophin ( $\beta$ hCG) using adjuvants permissible for human use (alum, muramyl dipeptide and sodium phthalyl derivative of lipopolysaccharide). The animals were monitored for anti-ZP3 antibody titres, biweekly progesterone concentrations, menstrual cyclicity and status of fertility. All the animals generated a good anti-ZP3 antibody response, continued to have ovulatory cycles, remained infertile in the presence of high anti-ZP3 antibody titres and showed no disturbance in cyclicity (except summer amenorrhoea). Examinations by laparoscope showed normal ovaries with developing follicles or corpora lutea on the surface. Fifty per cent of the animals conceived after a decline in antibody titres. Ovaries of animals that failed to regain fertility were examined for changes in morphology at times when anti-ZP3 antibody titres in the circulation were low and following a booster when titres were high. None of the ovaries showed any sign of inflammation or lymphocytic infiltration. Follicles at different stages of development were seen in all of the ovaries. No significant reduction in the number of follicles, except in one monkey (MRA 178), was observed. There was no increase in the numbers of atretic or degenerating follicles. The results showed that ZP3 immunization with permissible adjuvants could be used for immunocontraception without obvious ovarian changes.
\end{abstract}

\section{Introduction}

The mammalian oocyte is surrounded by an acellular envelope - the zona pellucida (Wassarman, 1988). The zona pellucida is composed of several families of acidic glycoproteins which mediate the initial recognition and binding of spermatozoa to oocyte and subsequent activation events during the fertilization process in a species-specific manner. This critical role in reproduction together with their tissue-specific nature have made the ZP glycoproteins potential candidate antigens for immunocontraception. Porcine zona pellucida (PZP) is used as an antigen because of its immunological crossreactivity with human zona pellucida and its availability in relatively large amounts (Sacco, 1987). The antifertility effect of active immunization with PZP antigens has been demonstrated in several animal models (Skinner et al., 1984; Mahi-Brown et al., 1985; Sacco et al., 1989). However, some of these studies have shown a transient (Sacco et al., 1983) or an irreversible (Skinner et al., 1984) alteration in the cyclicity, hormonal profiles and follicular development in ovaries of immunized animals. The efficacy of ZP3 immunization in female bonnet monkeys, Macaca radiata,

Received 11 October 1993. using adjuvants permissible for human use was investigated. Animals were evaluated with respect to their antibody titres, fertility status, hormonal profiles, cyclicity, ovarian histology and long-term follow up was carried out. The results showed that ZP3 adsorbed on alum with muramyl dipeptide (MDP) and sodium phthalyl derivative of lipopolysaccharide (SPLPS) can render the animals infertile without affecting ovarian function. The reversal of fertility in $50 \%$ of the immunized animals encourages continued investigation for suitable adjuvants or antigenic epitopes for PZP based contraceptive vaccines.

\section{Materials and Methods}

Preparation of porcine ZP3 antigens

Porcine ovaries were collected from an abattoir and stored at $-20^{\circ} \mathrm{C}$ until further processing as described by Yurewicz et al. (1987). Briefly, ovaries were minced and oocytes isolated by sieving through nylon meshes of decreasing pore sizes. The oocytes were homogenized in a glass-Teflon homogenizer and solubilized isolated zona pellucida was obtained by heating at 
$73^{\circ} \mathrm{C}$ for $20 \mathrm{~min} . \mathrm{ZP} 3$ was obtained by treating solubilized isolated zona pellucida with SDS and separating by chromatography on Sephacryl S-400 (Pharmacia LKB, Uppsala) and hydroxylapatite (Sigma Chemical Co., St Louis, MO) resins. SDS was removed by ion pair extraction and purity was confirmed by SDS-PAGE.

ZP3 was conjugated to $\beta$ hCG (obtained from P. Sahai, GMP-GLP Unit, National Institute of Immunology, New Delhi) in a I:1 molar ratio using the periodate method (Nakane and Kawaoi, 1974). In brief, $\beta \mathrm{hCG}$ was oxidized in $10 \mathrm{mmol}$ sodium metaperiodate $\mathrm{I}^{-1}$ overnight at $4^{\circ} \mathrm{C}$ and then dialysed against $20 \mathrm{mmol}$ acetate buffer $1^{-1}(\mathrm{pH} 4.4)$ and the $\mathrm{pH}$ adjusted to 9.5 with $0.5 \mathrm{~mol}$ bicarbonate $1^{-1}$. An equimolar amount of ZP3 in $50 \mathrm{mmol}$ bicarbonate $\mathrm{1}^{-1}, \mathrm{pH} 9.5$ was added, and the reaction mixture was shaken for $24 \mathrm{~h}$ at $4^{\circ} \mathrm{C}$ and the resulting conjugate used for immunizations.

\section{Immunization protocol}

Blood samples were collected twice a week from female bonnet monkeys of proven fertility reared at the Institute Primate Facility and serum progesterone concentrations were estimated. Animals showing at least two consecutive normal ovulatory cycles (peak serum progesterone $>2 \mathrm{ng} \mathrm{ml}^{-1}$; Bamezai, 1986) were selected for the study. Immunizations were done with two forms of antigen. In Group I $(n=4)$ primary immunizations consisted of three doses of $100 \mu \mathrm{g} \mathrm{ZP3}$ per injection adsorbed on alum and mixed with $1 \mathrm{mg}$ normuramyl-dipeptide octylamide (MDP: K. B. Mathur, Central Drug Research Institute, Lucknow) i.m. at monthly intervals. One milligram of sodium phthalyl derivative of lipopolysaccharide (SPLPS) prepared as described by Elin et al. (1981) was included in the first injection. The animals were boosted with $100 \mu \mathrm{g}$ ZP3 on alum with $1 \mathrm{mg}$ of MDP i.m. when a decline in anti-ZP3 antibody titres was observed. Blood samples $(I-2 \mathrm{ml})$ were collected twice a week from the ante-cubital vein for determination of hormone concentrations and antibody titre estimations. Animals were allowed to mate with males of proven fertility after the three primary injections.

In Group II $(n=4)$ primary immunization consisted of three injections given at monthly intervals and comprised ZP3$\beta$ hCG conjugate ( $100 \mu \mathrm{g}$ of $\mathrm{ZP} 3$ and $125 \mu \mathrm{g}$ of $\beta \mathrm{hCG}$ ). Subsequently, $100 \mu \mathrm{g}$ ZP3 alone was used for booster immunizations. The other immunization details were as for Group I.

\section{Assays for steroid hormones}

Serum progesterone concentration was determined by radioimmunoassay using the WHO Matched Assay Reagent Programme (Sufi et al., 1983). Each serum sample was run in duplicate. Steroids were extracted from serum $(0.1 \mathrm{ml})$ by adding $2 \mathrm{ml}$ of ice-cold ether to each tube and vortexing for $2 \mathrm{~min}$. The tube was dipped in liquid nitrogen to freeze the serum phase and the unfrozen ether phase containing extracted steroids was decanted into another tube. The ether was allowed to evaporate overnight; $0.5 \mathrm{ml}$ steroid assay buffer $(100 \mathrm{mmol}$ phosphate $1^{-1}, 150 \mathrm{mmol} \mathrm{NaCl} 1^{-1}, \mathrm{pH} 7.3$ with $0.01 \%$ thiomersal and $0.1 \%$ gelatin) was added and the tube vortexed vigorously. Anti-progesterone antibody $(0.1 \mathrm{ml}$ at dilution giving approximately $50 \%$ binding of $[3 \mathrm{H}]$ progesterone in the absence of unlabelled competing progesterone) and $0.1 \mathrm{ml}$ $\left[{ }^{3} \mathrm{H}\right]$ progesterone (10 000 c.p.m. per tube) were added and tubes incubated for $16 \mathrm{~h}$ at $4^{\circ} \mathrm{C}$. Unbound progesterone was separated by adding $0.2 \mathrm{ml}$ of ice-cold assay buffer containing $0.625 \%$ activated charcoal and $0.0625 \%$ dextran and incubating for $30 \mathrm{~min}$ at $4^{\circ} \mathrm{C}$ followed by centrifugation at $1800 \mathrm{~g}$ for $15 \mathrm{~min}$. The supernatant was decanted into vials with $4 \mathrm{ml}$ scintillation fluid $(0.4 \% \quad 2,5$ diphenoxazole; $0.01 \%$ POPOP [1-4 bis (5-phenyl-2-oxazolyl) benzene] in toluene) and radioactivity was measured in a liquid scintillation beta counter (LKB Rackbeta). The concentration of progesterone per millilitre serum was calculated from a standard curve set with known amounts of progesterone in each assay.

Oestradiol concentration was determined following a similar procedure except that $0.2 \mathrm{ml}$ serum was used for extraction of steroids.

\section{Anti-ZP3 antibody estimation}

Anti-ZP3 antibody titre was estimated by enzymelinked immunosorbent assay (ELISA). Microtitration plates were coated with solubilized isolated zona pellucida ( $1 \mu \mathrm{g}$ per well) in phosphate buffered saline (PBS; $50 \mathrm{mmol}$ phosphate $\mathrm{I}^{-1}$, $150 \mathrm{mmol} \mathrm{NaCl} \mathrm{l}{ }^{-1}, \mathrm{pH} \mathrm{7.4)}$ at $4^{\circ} \mathrm{C}$ overnight. All subsequent incubations were carried out at $37^{\circ} \mathrm{C}$ for $\mathrm{I} \mathrm{h}$. After each incubation, the plates were washed three times with PBS containing $0.05 \%$ Tween 20 (PBST). The plates were blocked with $1 \%$ BSA in PBS. Serial doubling dilutions of preimmune and immune sera were prepared in PBST containing $0.1 \%$ BSA. After blocking with BSA, $100 \mu \mathrm{l}$ of various dilutions of serum were added per well in duplicate. After washing, the plates were incubated with $100 \mu \mathrm{l}$ Protein A-horseradish peroxidase conjugate per well (Reagent Bank, National Institute of Immunology, New Delhi) at 1:4000 dilution. The plates were then washed and enzyme activity revealed by adding $100 \mu \mathrm{l}$ $0.05 \%$ orthophenylene diamine and $0.06 \% \mathrm{H}_{2} \mathrm{O}_{2}$ in $50 \mathrm{mmol}$ citrate phosphate $1^{-1} \mathrm{pH} 5.0$ to each well. The reaction was stopped after $20 \mathrm{~min}$ by adding $50 \mu \mathrm{l}$ of $2.5 \mathrm{~mol} \mathrm{H}_{2} \mathrm{SO}_{4} \mathrm{l}^{-1}$ per well and absorbance at $490 \mathrm{~nm}$ read on a Biotek ELISA reader. For each serum sample tested, a reciprocal of the dilution giving an absorbance of 1.0 was calculated by regression analysis and has been represented as antibody units. One serum sample from each assay was carried over to the next assay as an internal control. The interassay variation was less than $10 \%$. In addition, antibody titres were also expressed as absorbance at $490 \mathrm{~nm}$ at a serum dilution of 1:200 for all the animals except MRA 47 and MRA 86 which are expressed at 1:1600.

\section{Anti-hCG antibody titres}

Anti-hCG antibody titres were estimated by radioimmunoassay as described by Dubey et al. (1976). The results are represented as percentage of iodinated hCG bound to monkey serum at dilution of 1:400.

\section{Laparoscopy}

Examination by laparoscope was carried out in five out of eight monkeys at the indicated time points during the course of 
immunization. On the basis of the menstrual record of each animal a probable mid-cycle period from day 10 to day 16 of the cycle was selected for examination by laparoscope. Laparoscopy was carried out under ketamine hydrochloride ( $5 \mathrm{mg} \mathrm{kg}^{-1}$ body mass, i.m.) anaesthesia. Surgery was carried out using all aseptic precautions and the animals received analgesic (analgin $10 \mathrm{mg} \mathrm{kg}^{-1}$ body mass day ${ }^{-1}$ ) and antibiotic (tetracyclin $4 \mathrm{mg} \mathrm{kg}^{-1}$ body mass day ${ }^{-1}$ ) for 5 days after surgery. Ovaries were examined for the presence of follicles, corpora lutea or cysts.

\section{Ovarian histology}

Unilateral ovariectomy was performed in animals that failed to become pregnant after a decline in anti-ZP3 antibody titres. Ovaries from two animals that showed a reversible antifertility effect and two unimmunized animals were also examined. After ovariectomy, some animals were boosted with $100 \mu \mathrm{g}$ ZP3 and the second ovary removed after 6 weeks when the anti-ZP3 antibody titres were high. The ovaries were fixed in Bouin's fixative for $24 \mathrm{~h}$ and then embedded in paraffin wax. Serial sections of $5 \mu \mathrm{m}$ were cut and stained by haematoxylin and eosin. For each ovary, 20 nonadjacent sections were randomly chosen and examined for the presence of follicles at different stages of development or for cystic changes or lymphocytic infiltration. The numbers of primordial follicles with a central oocyte surrounded by a single layer of flattened granulosa cells, secondary follicles with several layers of granulosa cells and tertiary follicles with the oocytes surrounded by an antrum lined with multiple layers of granulosa cells were counted. In addition, the numbers of degenerating or atretic follicles were also counted. The data were analysed by Student's $t$ test for significant reduction in number of follicles between control and immunized animals.

\section{Results}

\section{Group I}

The monkeys in this group were immunized with $100 \mu \mathrm{g}$ ZP3 per injection and they developed antibody titres in the range of 1500-6000 antibody units (Fig. 1). For comparison, anti-ZP3 antibody titres are also expressed as absorbance at $490 \mathrm{~nm}$ at a single dilution of 1:200. The titres were sustained for approximately 6 weeks after which the animals received a booster injection. The booster injection was followed by a secondary response. However, repeated boosters were required to sustain the antibody titres. The menstrual records of the animals showed that they were regularly cyclic except for the period of summer amenorrhoea. Progesterone profiles also confirmed this observation and showed that the animals were ovulating (peak progesterone $>2 \mathrm{ng} \mathrm{ml}^{-1}$ ). However, one animal (MRA 178) showed some anovulatory cycles shortly after immunization. Disturbance in cyclicity was seen from May to August coinciding with the summer amenorrhoea seen in $M$. radiata (Srinath, 1980). The amenorrhoea was unrelated to the circulating anti-ZP3 antibody titres. A return to normal cyclicity with ovulation was observed after summer amenorrhoea which lasted 2-3 cycles. Examination of two animals by laparoscope (Fig. 2) showed developing follicles on the surface of the ovaries. After a decline in antibody titres, one animal (MRA 293) became pregnant within 8 months and delivered a full-term, normal healthy offspring. However, the other animals in this group failed to become pregnant.

\section{Group II}

A conjugate of ZP3 and $\beta$ hCG was used to immunize this group of animals, to test the potential of polyvalent vaccines for immunocontraception. However, ZP3 alone was used in the booster injections. In all the animals, anti-hCG antibody titres declined $\left(<10 \%\right.$ binding of ${ }^{125}$ I-labelled hCG in radioimmunoassay) before 320 days after immunization showing that the subsequent antifertility effect was maintained owing to the circulating anti-ZP3 antibody titres (Fig. 3). The animals injected with ZP3- 3 hCG developed higher anti-ZP3 antibody titres following primary immunization - in the range of 4000 to 14000 antibody units. Summer amenorrhoea was seen in all animals. One animal (MRA 49) showed a transient increase in basal progesterone values for 12 weeks between 500 to 600 days after immunization associated with normal menstrual cyclicity. However, the profile showed a normal range of progesterone after the following summer. Another animal (MRA 47) became pregnant in two cycles after the decline in antibody titre and successfully delivered a healthy, normal offspring. One animal (MRA 86) conceived but aborted in the fourth month of gestation. Another animal (MRA 130) showed anovulatory cycles after the primary injection. However, ovulatory cycles resumed in spite of high anti-ZP3 antibody titres. The animal conceived in four cycles following a decline in antibody titres. The pregnancy was carried to term delivering a full term normal pup. Examination by laparoscope was performed for all the monkeys in this group (see Fig. 3). One of the animals (Fig. 2) showed a follicle on the left ovary, while another animal (MRA 86) showed a hyperaemic region suggestive of a freshly formed corpus luteum. A corpus luteum was also seen in the laparoscopic examination of two animals.

\section{Oestradiol concentration}

Circulating concentrations of oestradiol were estimated for two to three consecutive cycles in each animal. The circulating basal and peak oestradiol concentrations in all the animals except two were not significantly different from the preimmune levels (Table 1 ). These two animals showed a significant decrease $(P<0.05)$ in the peak oestradiol concentrations when the anti-ZP3 antibody titres were high.

\section{Ovarian histology}

The histology of the ovaries of all the animals from Group I and three animals from Group II were studied for effects of ZP3 immunization. Ovaries from two unimmunized animals served as controls. A large variation in the numbers of primordial and secondary follicles was seen between the controls. However, both animals were of proven fertility.

In all the animals immunized with porcine ZP3 and ZP3$\beta$ hCG conjugate, no signs of inflammation were seen in any of 
(a)
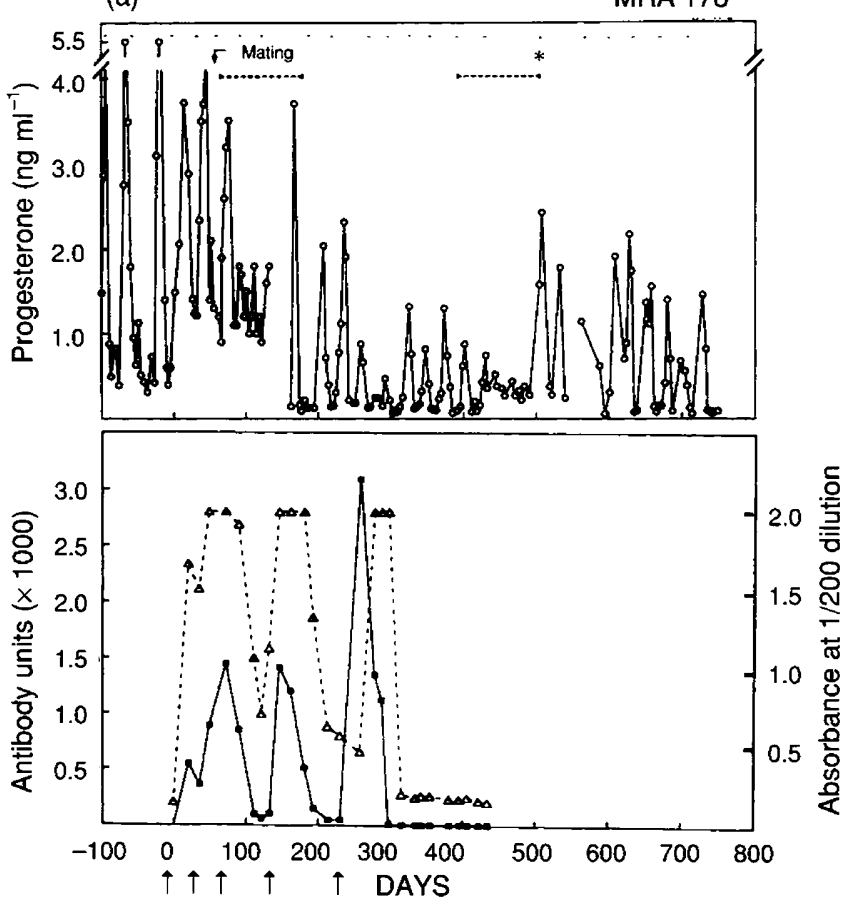

(c)
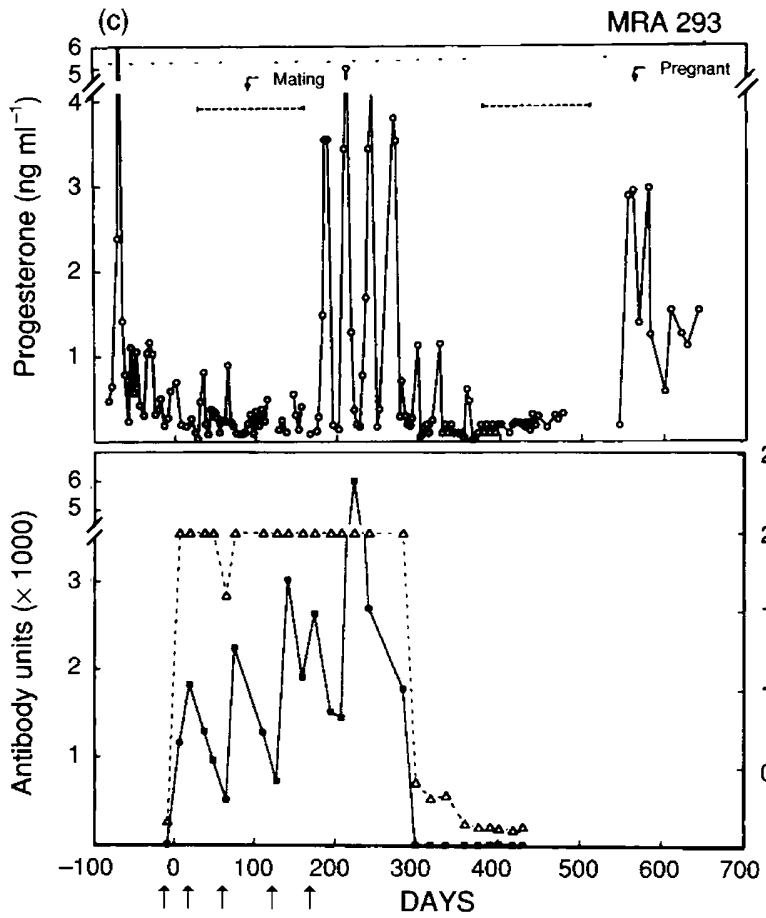

2.5

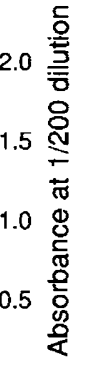

(b)
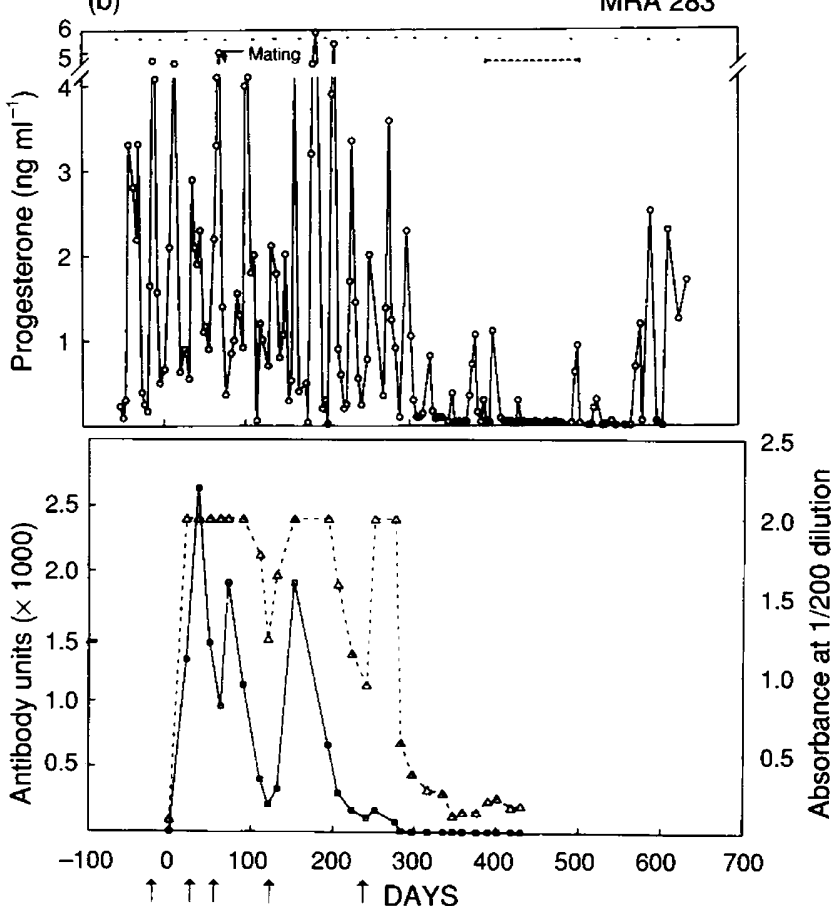

(d)
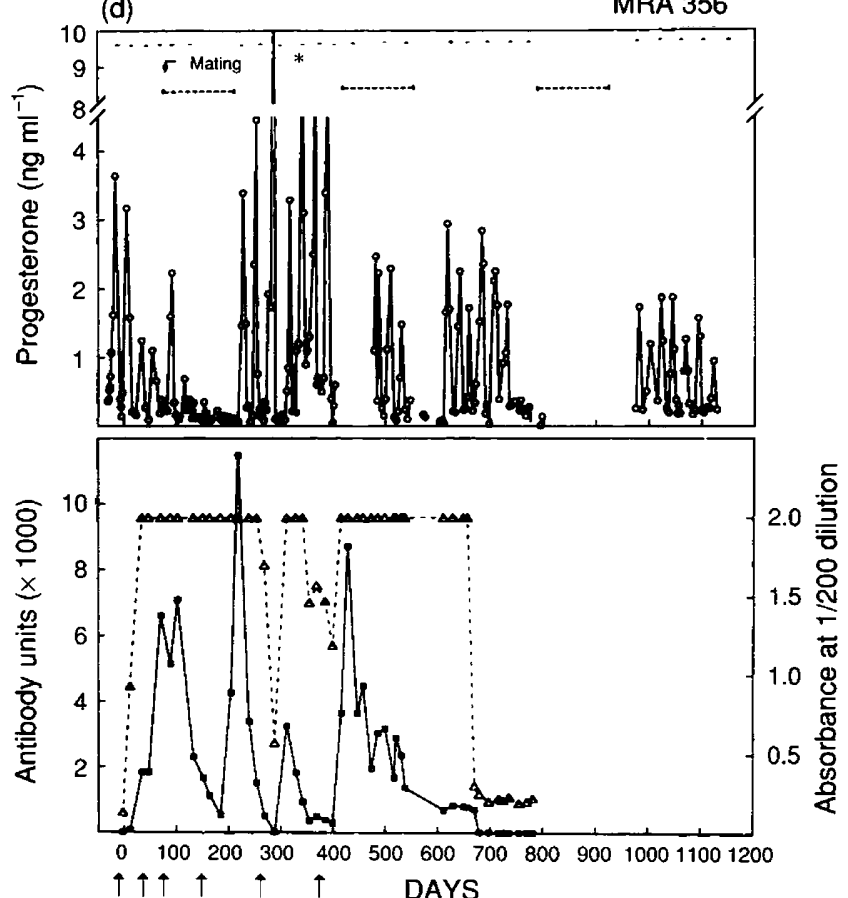

Fig. 1. Progesterone profiles, menstrual cycles and anti-ZP3 antibody titres of bonnet monkeys (Group 1) immunized with ZP3. The upper panel of each section of this figure shows the serum progesterone concentrations in $\mathrm{ng} \mathrm{ml}^{-1}(\supset)$. Arrows $(\downarrow)$ indicate initiation of mating or onset of pregnancy (MRA 293), (--) summer amenorrhoea, $\left(^{*}\right)$ laparoscopy and $(\cdots)$ menstrual bleeding. The lower panel shows the anti-ZP3 antibody titres as antibody units $(\square)$ and also as absorbance in ELISA at a single dilution of $1 / 200(\Delta)$. Immunization schedule is indicated by arrows $(\uparrow)$.

the sections examined. The histology of the ovary was normal showing follicles in all stages of development (Fig. 4). No cysts, cell clusters or lymphocytic infiltration was seen. No significant increase in the number of atretic follicles or follicles without oocytes was observed in the immunized animals as compared with the controls. Corpora lutea were seen in the ovaries from two animals. The results are summarized in Table 2. Statistical analysis using Student's $t$ test showed that, except for one 

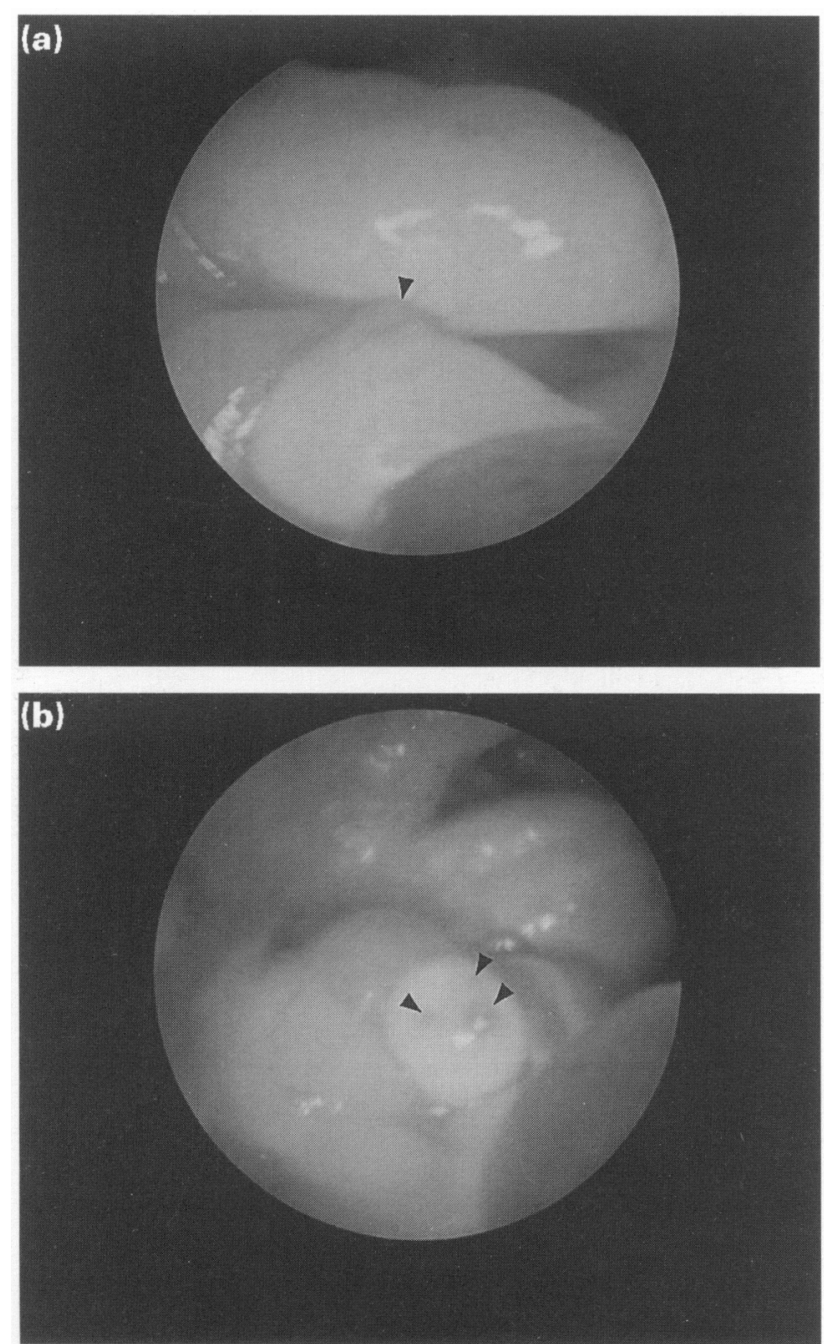

Fig. 2. Representative photographs of examination by laparoscope of animals immunized with $\mathrm{ZP} 3$ or $\mathrm{ZP} 3-\beta \mathrm{hCG}$ conjugate. (a) A single large follicle (arrowhead) on the ovary of MRA 49 (immunized with ZP3- $\beta$ hCG) and (b) MRA 178 (immunized with ZP3) with one large and three small follicles (arrowheads). There is no obvious pathology of the ovaries on gross examination.

animal (MRA 178) there was no significant depletion in primary, secondary or tertiary follicles in immunized animals compared with the control (MRA 539). One animal (MRA 178) showed significantly $(P<0.005)$ fewer secondary and tertiary follicles. However, there was no depletion in the primordial follicle pool compared with the control. The differences in numbers of follicle in the ovaries removed at points of low or high anti-ZP3 antibody titres were also not significant.

\section{Discussion}

Zona pellucida antigens have been effectively used for immunocontraception in several animal models. Results of immunization studies using crude zona pellucida show that the prevention of fertility in vivo is due to ovarian dysfunction (Skinner et al., 1984), in which a complete destruction of primordial and developing follicles with formation of cell nests and luteal cysts was observed. Further investigations have been directed towards immunization with purified zona pellucida preparations which may allow normal folliculogenesis and ovulation but inhibit sperm-egg interaction, thereby leading to infertility. The extent of the ovarian pathology can be minimized by using purified ZP3. Sacco ef al. (1983) showed that immunization with purified ZP3 was associated with only a transient alteration of oestradiol concentrations in squirrel monkeys. However, the long-term effects of this immunization was not demonstrated in their study. Rabbits immunized with deglycosylated ZP3 show normal ovarian function in terms of follicular development and hormonal secretion with concomitant infertility (Jones et al., 1992). In primate models, the use of deglycosylated ZP3 in baboons (Dunbar et al., 1989) showed decreased concentrations of oestrogen followed by a cessation of ovulation, whereas deglycosylated ZP3 $\beta$ in marmoset monkeys (Paterson et al., 1992) was associated with depletion of the primordial follicle pool in the ovary. The efficacy of deglycosylated ZP3 in causing infertility encouraged the investigation of well-defined peptide immunogens as contraceptive vaccine candidates. Immunizations in the mouse model with a mouse ZP3 peptide ( 328 to 342 ) conjugated to keyhole limpet haemocyanin in random bred NIH Swiss mice causes long-term reversible antifertility (Millar et al., 1989), whereas the same peptide in complete Freund's adjuvant (CFA) given to $(\mathrm{C} 57 \mathrm{Bl} / 6 \times \mathrm{A} / \mathrm{J}) \mathrm{F}_{1}$ mice causes severe autoimmune oophorites (Rhim et al., 1992). Upadhyay et al. (1989) evaluated the influence of adjuvants like CFA and alum in ovarian dysfunction when administered with ZP3 in bonnet monkey and CFA was implicated in causing extensive morphological aberration with a disruption in folliculogenesis. These studies suggest a species-specific susceptibility to ovarian dysfunction with zona immunization. The study reported here shows that immunization with purified ZP3 leads to infertility without interfering with the ovarian function of female bonnet monkeys. The anti-porcine ZP3 antibodies react with bonnet monkey zonae pellucidae when tested by indirect immunofluorescence on frozen sections from normal monkey ovaries (data not shown). The effect of these antibodies on monkey sperm-egg interaction remains to be elucidated; however, the re-established fertility in $50 \%$ of the animals after a decline in anti-ZP 3 antibody titres suggests that the effect could be a direct action of the antibodies at the level of the sperm-egg interaction.

Previous studies in bitches, squirrel monkeys and marmosets using alum as adjuvant have demonstrated a variable efficacy in protection from conception. A comparative study of different adjuvants with crude and purified zona pellucida preparations in bitches (Mahi-Brown et al., 1985) showed that the antibody response generated by using alum was low, but sufficient to protect the animal from pregnancy in the first cycle after immunization. In marmosets, alum with ZP3 generated a protective immune response in only one of four animals immunized (Paterson et al., 1992). The ovarian histology of this animal showed a normal follicular development except for the presence of follicular cell clusters.

Alum as an adjuvant, failed to generate a good antibody response in squirrel monkeys immunized with ZP3 (Sacco et al., 1989). The polyclonal sera from these monkeys did not show 

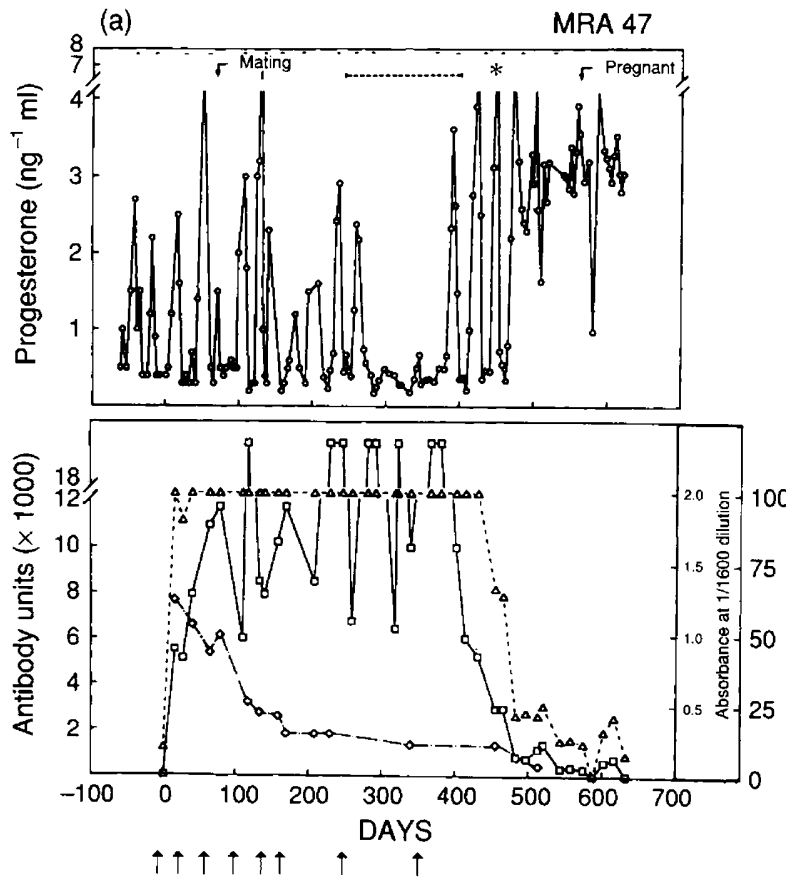

(c)

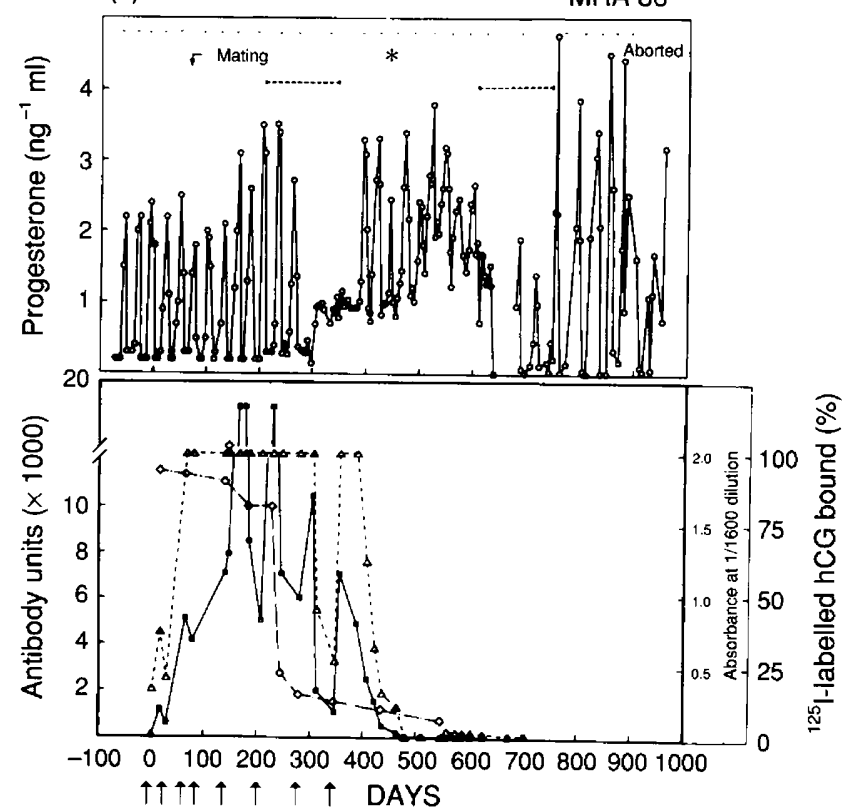

(b)
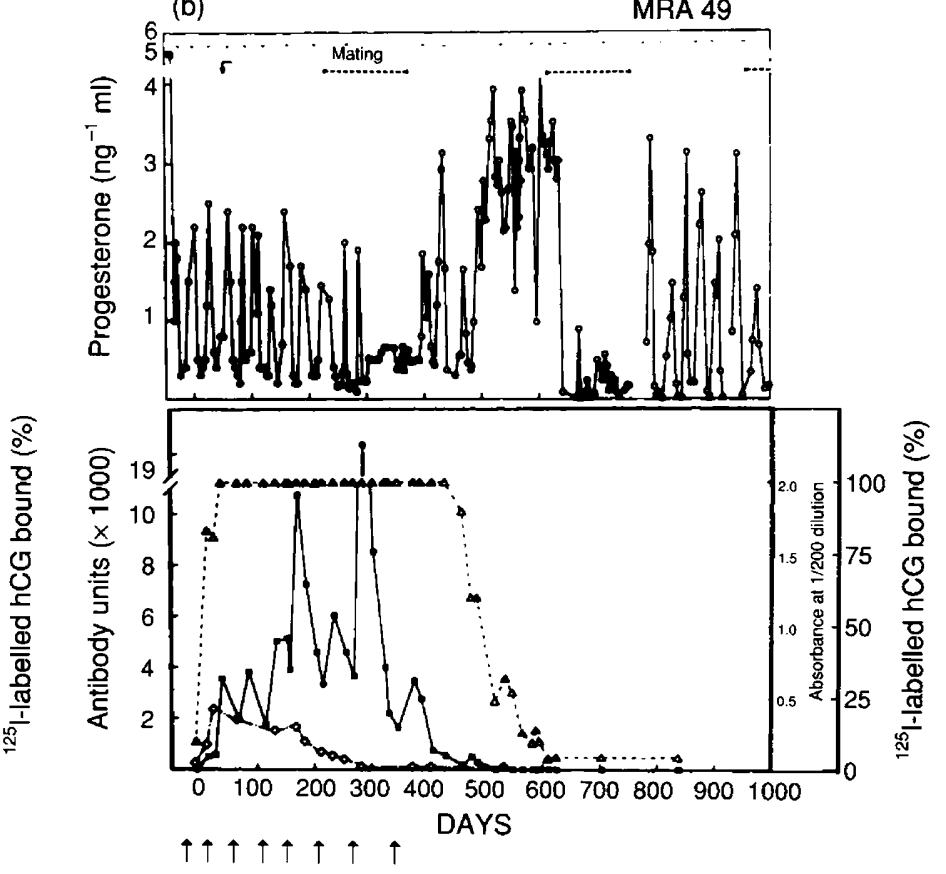

(d)
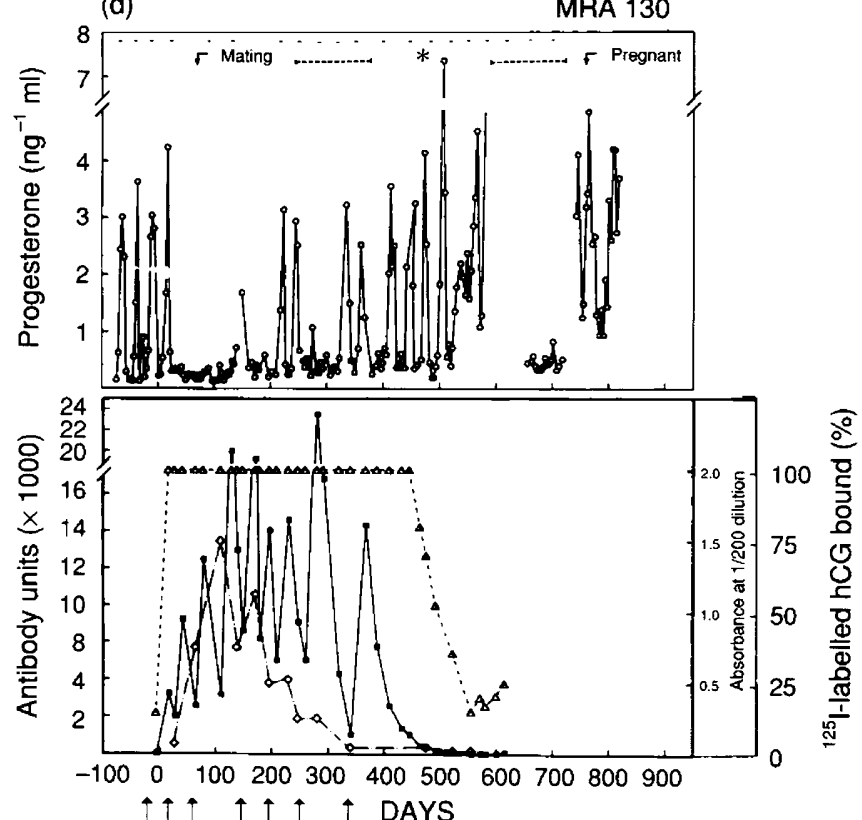

Fig. 3. Progesterone profiles, menstrual cycles and anti-ZP3 antibody titres of bonnet monkeys (Group 2) immunized with ZP3- $\beta$ hCG conjugate. The upper panel of each figure shows the serum progesterone concentrations in $\mathrm{ng} \mathrm{ml}^{-1}(0)$. Arrows $(\downarrow)$ indicate initiation of mating or onset of pregnancy (MRA 47 and MRA 130), (--) summer amenorrhoea, $(*)$ laparoscopy and $(\cdots)$ menstrual bleeding. The lower panel shows the anti-ZP3 antibody titres as antibody units ( $\square$ ) and also as absorbance in ELISA at a single dilution of $1 / 200$ or $1 / 1600$ ( $\triangle$ ). The circulating anti-hCG antibody titres are represented as percentage binding of ${ }^{125} \mathrm{I}$-labelled hCG at a serum dilution of $1 / 400(\diamond)$. Immunization schedule is indicated by arrow $(\uparrow)$.

potential for antifertility when tested in vitro in a porcine sperm-egg binding assay. MDP, however, was an efficient adjuvant in this system and generated a good response against ZP3. However, the results of our study show that ZP3 adsorbed on alum and injected with MDP or SPLPS can protect animals from pregnancy for 6-20 ovulatory cycles. The ovarian function was normal throughout the duration of the study except during summer amenorrhoea.

The animals in Group 1 showed a variation in the peak progesterone levels achieved per cycle. However, $>60 \%$ of 
Table 1. Serum oestradiol concentration $\left(\mathrm{pg} \mathrm{ml}^{-1}\right.$ ) in bonnet monkeys immunized with porcine $\mathrm{ZP} 3$ or ZP3- $\beta$ hCG conjugate

\begin{tabular}{|c|c|c|c|c|c|c|c|c|c|}
\hline \multirow[b]{2}{*}{ Group } & \multicolumn{3}{|c|}{ Preimmune } & \multicolumn{3}{|c|}{ High titre } & \multicolumn{3}{|c|}{ Low titre } \\
\hline & \multicolumn{2}{|c|}{ Peak } & Basal & \multicolumn{2}{|c|}{ Peak } & Basal & \multicolumn{2}{|c|}{ Peak } & \multirow[t]{2}{*}{ Basal } \\
\hline \multicolumn{9}{|l|}{ Group I } & \\
\hline MRA 178 & 109 & \pm 18 & $50.3 \pm 14$ & $54 \pm$ & $12^{\mathrm{a}}$ & $18 \pm 8$ & & D & ND \\
\hline MRA 283 & 140 & \pm 9 & $60.5 \pm 11$ & $133 \pm$ & 21 & $31.3 \pm 16$ & & D & ND \\
\hline MRA 293 & 127 & \pm 9 & $38.3 \pm 8$ & $215 \pm$ & 65 & $45.6 \pm 27$ & & D & ND \\
\hline MRA 356 & 165 & \pm 40 & $38 \pm 17$ & $82.5 \pm$ & 22 & $33 \pm 8$ & 87. & \pm 18 & $23 \pm 7$ \\
\hline \multicolumn{10}{|l|}{ Group 2} \\
\hline MRA 47 & 84. & \pm 27 & $20 \pm 4$ & $112 \pm$ & 31 & $33 \pm 4$ & 108 & \pm 31 & $28 \pm 2$ \\
\hline MRA 49 & 116 & \pm 32 & $39.6 \pm 10$ & $293 \pm$ & 147 & $48.5 \pm 5$ & 111 & \pm 8 & $36.6 \pm 3$ \\
\hline MRA 86 & 217 & \pm 43 & $56.3 \pm 4$ & $73.6 \pm$ & $13^{a}$ & $47 \pm 13$ & 274 & \pm 68 & $49 \pm 4$ \\
\hline MRA 130 & 125 & \pm 24 & $35 \pm 12$ & $96 \pm$ & 5 & $27.5 \pm 3$ & 172 & \pm 26 & $38.5 \pm 4.5$ \\
\hline
\end{tabular}

Values are means \pm so from two or three cycles.

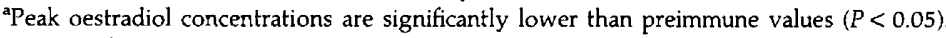

ND: not done.

Table 2. Stages of follicle development in bonnet monkeys immunized with porcine ZP3 or ZP3- $\beta$ hCG conjugate

\begin{tabular}{|c|c|c|c|c|c|c|}
\hline \multirow[b]{2}{*}{ Antigen } & \multirow[b]{2}{*}{ Animal number } & \multicolumn{4}{|c|}{ Follicles } & \multirow[t]{2}{*}{ Corpus luteum } \\
\hline & & Primary & Secondary & Tertiary & Degenerating & \\
\hline \multirow[t]{2}{*}{ Control } & MRA 539 & $15.3 \pm 0.8$ & $6.8 \pm 0.4$ & $2.7 \pm 0.2$ & $2.2 \pm 0.3$ & \\
\hline & MRA 277 & $81.2 \pm 4.0$ & $22.5 \pm 1.0$ & $2.3 \pm 0.2$ & $2.8 \pm 0.2$ & \\
\hline \multirow[t]{5}{*}{ Group $1 \mathrm{ZP} 3$} & MRA 356 & $86.3 \pm 4.1$ & $18.3 \pm 1.1$ & $4.0 \pm 0.3$ & $1.5 \pm 0.2$ & \\
\hline & MRA 178 & $29.8 \pm 4.3$ & $2.0 \pm 0.6^{b}$ & $1.2 \pm 0.6^{b}$ & $2.8 \pm 0.5$ & \\
\hline & MRA $178^{a}$ & $27.7 \pm 2.3$ & $4.1 \pm 0.4^{\mathrm{b}}$ & $1.0 \pm 0.2^{b}$ & $3.0 \pm 0.3$ & + \\
\hline & MRA 283 & $41.7 \pm 3.2$ & $10.0 \pm 0.9$ & $4.2 \pm 0.3$ & $1.5 \pm 0.1$ & \\
\hline & MRA 293 & $116.0 \pm 7.0$ & $32.3 \pm 3.0$ & $1.4 \pm 0.2$ & $3.0 \pm 0.3$ & \\
\hline \multirow[t]{5}{*}{ Group 2 ZP3- $\beta$ hCG } & MRA 49 & $13.6 \pm 2.1$ & $8.5 \pm 1.1$ & & & + \\
\hline & MRA 86 & $103.0 \pm 10.5$ & $10.5 \pm 1.8$ & $1.5 \pm 0.3$ & $2.6 \pm 0.4$ & \\
\hline & MRA $86^{\circ}$ & $81.6 \pm 8.1$ & $9.8 \pm 1.8$ & $2.2 \pm 0.5$ & $2.5 \pm 0.3$ & \\
\hline & MRA 130 & $98.0 \pm 7.9$ & $22.6 \pm 1.5$ & $1.8 \pm 0.4$ & $2.0 \pm 0.3$ & \\
\hline & MRA $130^{2}$ & $111.0 \pm 8.7$ & $10.7 \pm 0.8$ & $2.3 \pm 0.4$ & $2.4 \pm 0.4$ & \\
\hline
\end{tabular}

Values are expressed as average number of follicles per section from 20 nonadjacent sections.

${ }^{2}$ Ovaries removed following a booster with $\mathrm{ZP} 3$, when anti-ZP3 antibody titres were high.

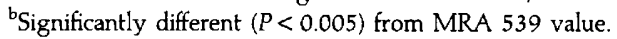

the cycles in the fertile period were ovulatory. One of the animals had fewer ovulatory cycles $(38 \%)$ with peak progesterone concentrations $>2 \mathrm{ng} \mathrm{ml}^{-1}$.

The peak oestradiol concentrations in two animals were also significantly $(P<0.05)$ lower after immunization. The oestradiol concentrations in all other animals at times of high titres of circulating anti-ZP3 antibodies or following their decline, were not significantly different from the preimmune levels.

Fifty per cent of the animals became pregnant after the decline in antibody titres; however, one of the four animals aborted after 4 months of gestation. The other three animals carried the pregnancy to term and delivered normal, healthy pups. These pups are now 6-12 months old and show a normal pattern of growth. Although our investigations do not explain the cause of irreversible infertility in $50 \%$ of the animals, the histology of all the animals was normal. The animal that showed significantly fewer secondary and tertiary follicles also showed the presence of a corpus luteum, suggesting that the animal continued to ovulate until ovariectomy was performed. The reversibility of the fertility status is not related to the peak anti-ZP3 antibody titres attained by the respective animals. One animal in Group I and two animals in Group II that regained fertility subsequently to decline in anti-ZP3 antibody titres had peak antibody titres higher or equivalent to those of the other animals in their respective groups. In the absence of any other obvious reason, the factor requiring consideration 

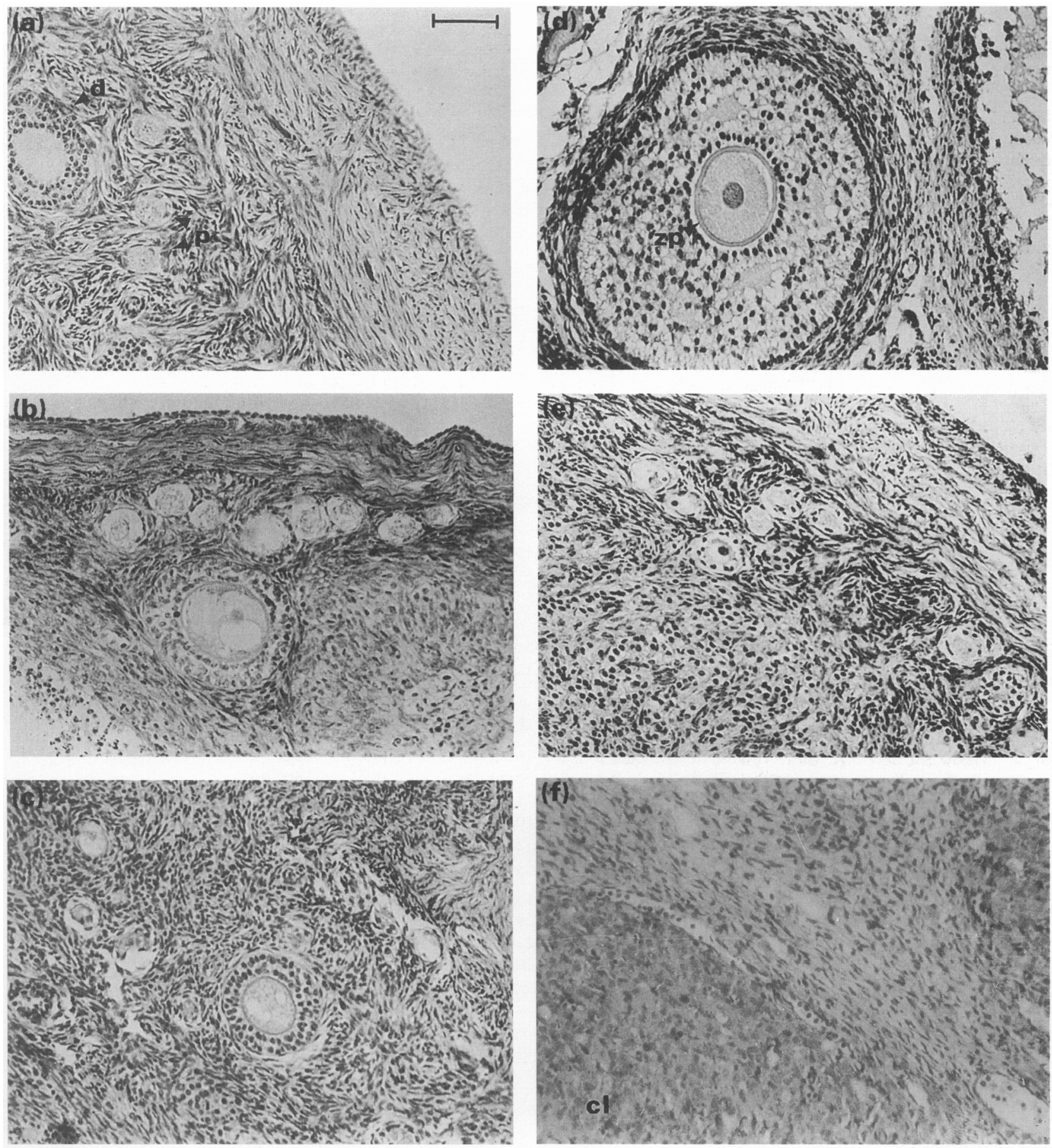

Fig. 4. Photomicrographs of ovarian sections of unimmunized bonnet monkeys or those immunized with ZP3 or ZP3- $\beta$ hCG conjugate. The sections were stained with haematoxylin and eosin. (a) Ovarian morphology from unimmunized (control) animal with primordial (p) and developing (d) follicles (b)-(d) ovarian sections from ZP3 immunized animals showing follicles in different stages of development. Normal folliculogenesis and a corpus luteum (cl) were also seen in ZP3- $\beta$ hCG immunized animals (e and f). Scale bar represents $100 \mu \mathrm{m}$.

in evaluating the reversibility of ZP3 immunization is the captive colony fertility rate, which is $70 \%$ in our bonnet monkey colony.

Taken together these results do not seem to indicate impairment of ovarian function and are therefore promising, but, with this number of animals, ovarian dysfunction by ZP3 immunization cannot be excluded altogether. Current efforts in our laboratory are focused on delineation of functionally relevant epitopes on porcine $\mathrm{ZP} 3 \alpha$ and $\mathrm{ZP} 3 \beta$ and their sequence similarity to human and primate zona pellucida. 
Synthetic peptides corresponding to such regions having only B-cell epitopes and devoid of T-cell epitopes may be promising candidates to evaluate for their potential for immunocontraception.

This work was supported by a Contraceptive Development and Research in Immunology (CD\&RI)-USAID and Department of Biotechnology, India grant under an Indo-US collaborative research proposal. The views expressed by the authors do not necessarily reflect the views of the funding agencies. The technical assistance of S. Rajalakshmi, R. K. Thapa, J. P. Sharma and R. B. Singh is gratefully acknowledged.

\section{References}

Bamezai A (1986) Development of Hybridomas against Zona Pellucida Antigens and Their Bioefficacy $\mathrm{PhD}$ Thesis All India Institute of Medical Sciences, New Delhi

Dubey SK, Salahuddin M, Shastri N and Talwar GP (1976) Immunological properties of dinitrophenyl derivatives of beta subunit of human chorionic gonadotropin Contraception 13 141-152

Dunbar BS, Lo C, Powell J and Stevens VC (1989) Use of a synthetic peptide adjuvant for the immunization of baboons with denatured and deglycosylated pig zona pellucida glycoproteins Fertility and Sterility 52 311-318

Elin RJ, Wolf SM, McAdam KPW, Audibert F, Bernard C and Oberling F (1981) Preparation and reference $E$. coli endotoxin and its phthalylated derivative in humans Joumal of Infectious Diseases 144 329-336

Jones GR, Sacco AG, Subramanian MG, Kruger M, Zhang S, Yurewicz EC and Moghissi KM (1992) Histology of female rabbits immunized with deglycosylated zona pellucida macromolecules of pigs Journal of Reproduction and Fertility 95 513-525

Mahi-Brown CA, Yanagimachi R, Hoffman JC and Huang Thomas TTF (1985) Fertility control in bitch by active immunization with porcine zonae pellucidae: use of different adjuvants and patterns of estradiol and progesterone levels in estrous cycles Biology of Reproduction 32 761-772

Millar SE, Chamow SM, Baur AW, Oliver C, Robey F and Dean J (1989) Vaccination with a synthetic zona peptide produces long term contraception in female mice. Science 246 935-938
Nakane PK and Kawaoi A (1974) Peroxidase labeled antibody: a new method of conjugation Journal of Histochemistry and Cytochemistry 22 1084-1091

Paterson M, Thillai-Koothan P, Morris KD, O'Byrne K, Braude P, Williams A and Aitken RJ (1992) Analysis of the contraceptive potential of antibodies against native and deglycosylated porcine ZP3 in vivo and in vitro Biology of Reproduction 46 523-534

Rhim SH, Millar SE, Robey F, Luo AM, Lou YH, Yule T, Allen P, Dean J and Tung KSK (1992) Autoimmune disease of the ovary induced by a ZP3 peptide from the mouse zona pellucida Journal of Clinical Investigation $\mathbf{8 9}$ $28-35$

Sacco AG (1987) Zona pellucida: current status as candidate antigen for contraceptive vaccine development American Joumal of Reproductive Immunology 15 122-130

Sacco AG, Subramanian MG, Yurewicz EC, DeMayo FJ and Dukelow WR (1983) Heteroimmunization of squirrel monkeys (Saimiri sciureus) with a purified porcine zona antigen (PPZA): immune response and biologic activity of antiserum Fertility and Sterility 39 350-358

Sacco AG, Yurewicz EC and Subramanian MG (1989) Effect of varying dosages and adjuvants on antibody response in squirrel monkeys (Saimiri sciureus) immunized with the porcine zona pellucida $M_{\mathrm{r}}=55,000$ glycoprotein (ZP3) American Joumal Reproductive Immunology 21 1-8

Skinner SM, Mills T, Kirchick HJ and Dunbar BS (1984) Immunization with zona pellucida proteins results in abnormal ovarian follicular differentiation and inhibition of gonadotropin induced steroid secretion Endocrinology 115 2418-2432

Srinath BR (1980) Husbandry and breeding of bonnet monkeys (Macaca radiata) In Non Human Primate Models for Study of Human Reproduction, pp 17-22 Ed. TC Anandkumar. Krager, Basel.

Sufi SB, Donaldson A and Jeffcoate SL (1983) WHO Matched Assay Reagent Programme Method Manual, pp 71-85 WHO, Geneva

Upadhyay SN, Thillai-Koothan P, Bamezai A, Jayaraman S and Talwar GP (1989) Role of adjuvants in inhibitory influence of immunization with porcine zona pellucida antigen (ZP-3) on ovarian folliculogenesis in bonnet monkeys: a morphological study Biology of Reproduction 41 665-673

Wassarman PM (1988) Zona pellucida glycoproteins Annual Review of Biochemistry 57 415-442

Yurewicz EC, Sacco AG and Subramanian MG (1987) Structural characterization of the $M_{\mathrm{r}}=55,000$ antigen (ZP3) of porcine oocyte zona pellucida Journal of Biological Chemistry $262564-571$ 